Vol.10(3), pp. 54-60, March 2018

DOI: 10.5897/JAERD2017.0877

Articles Number: EBE646956133

ISSN 2141-2170

Copyright (C)2018

Author(s) retain the copyright of this article

http://www.academicjournals.org/JAERD
Journal of Agricultural Extension and Rural Development

\title{
Influence of social networks and social support on credit utilization in the Savings and Credit Cooperatives in Soroti District, Uganda
}

\author{
D. Alio ${ }^{1 *}$, J. J. Okiror ${ }^{1}$, J. G. Agea ${ }^{1}$, F. B. Matsiko ${ }^{1}$ and W. Ekere ${ }^{2}$ \\ ${ }^{1}$ Department of Extension and Innovation Studies, Makerere University, Uganda. \\ ${ }^{2}$ Department of Agribusiness and Natural Resource Economics, Makerere University, Uganda.
}

Received 11 April, 2017; Accepted 11 December, 2017

\begin{abstract}
Microfinance models and programs tend to mimic local people's support systems, especially their social networks, to ensure high repayment rate, efficient administration, and effective economic decisions. However, there is limited empirical evidence of their influence on credit use decisions. This paper examines the influence of social networks and social support on credit use decisions among SACCO members in Soroti district. Two hundred and fifty seven (257) respondents were randomly selected for study from Eleven SACCOs that were purposively selected from the five sub counties in the district. Data were collected using a cross-sectional questionnaire survey and analyzed using descriptive statistics, Chi-square analysis and regression analysis. Findings from this study revealed that the variability of the social networks was generally high but negatively related to credit utilization. Findings further indicate that effective utilization of credit is not necessarily dependent on the variability of social support accessed from social networks. Therefore, to ensure effective utilization of credit, SACCOs should disburse credit to borrowers with few network members but who are educationally, economically and occupationally privileged.
\end{abstract}

Key words: Social networks, social support, credit utilization.

\section{INTRODUCTION}

Microfinance models and programs tend to mimic local people's support systems, especially their social networks, to ensure high repayment rate, efficient administration and effective economic decisions. However, there is limited empirical evidence of their influence on credit use decisions. In Africa, the poor rely on their social networks to increase access to credit due to their limited sources of income (Mwangi and Kimani, 2015). In Uganda, the rural credit system is composed of a number of actors who interact to provide information on credit source as well as provide financial support to each other. These include relatives and friends who constitute $67 \%$ of total credit transactions, savings and credit cooperatives (SACCOs), money lenders, community based

*Corresponding author. E-mail: deborah.alio@yahoo.com.

Author(s) agree that this article remain permanently open access under the terms of the Creative Commons Attribution License 4.0 International License 
organizations and Non-Government Organizations (NGOs) (Nathan et al., 2004). However, cases of credit diversion continue to be a common phenomenon among the rural poor communities (Dasqupta and Dey, 2015; Oluyombo, 2013; Muhumuza, 2013). Some scholars have argued that it is important to use credit for economic activity so that it can generate sufficient income and help in economic upliftment of the borrower households and that unproductive use of credit blurs such achievement (Vedamurthy et al., 2015).

Social networks are sets of actors linked by social relations or ties (Knoke and Yang, 2008; Kebede and Butterfield, 2009) from which resources may be derived (Obaa and Mazur, 2016). Chai et al. (2016) defined social networks as particularistic relationships formed and maintained by interactive and stable kinship, friends, relatives, neighbors or territorial ties. Networks are important sources of information and other resources (Obaa and Mazur, 2016). In addition, the existence of social relations in the form of indigenous networks and norms of association are seen as substitutes for the physical collateral like land ownership which the poor lack, in the selection of loan beneficiaries, loan disbursal and recovery (Mugabi, 2010). Social support is "the social resources that persons perceive to be available or that are actually provided to them by formal support groups and informal helping relations (Cohen et al., 2000; Gottlieb and Bergen, 2010). The social support provided could be in the form of instrumental, emotional and social support (Vander Poel, 1993). Instrumental support entails supplying material or tangible support through goods or services, emotional support involves giving advice and talking about personal problems while social companionship implies sharing of social activities (Vander Poel, 1993) or encouraging people to join groups as way of solving credit problems. However, the kind of support will greatly depend on the network characteristics such as the composition and heterogeneity of individuals in the network.

Many studies on social networks have assessed social capital and access to credit (Okten and Osili, 2004), social capital on consumer default (Clark et al., 2014) as well as the effect of social capital on poverty alleviation (Idris and Agbim, 2015). In Uganda, previous studies by Obaa and Mazur (2016), Okten and Osili (2004) have focused more on social networks and access to credit. However, there is limited empirical evidence on influence of social networks on credit use decisions. For example, Mugabi (2010) investigated the impact of micro-credit utilization on household income and found that social support in the form of group solidarity is an important form of collateral security among low income earners in Iganga. He further recommended an investigation on the influence of social networks and social support on credit utilization. This paper examines the influence of social networks and social support on credit utilization. It is hypothesized that the higher the variability of the social networks, the more chances to access more social support from various sources and therefore the more effectively credit will be utilized.

\section{METHODOLOGY}

This study was conducted between January and April 2015 in Soroti District of Uganda. The study used a cross-sectional design whereby data were collected at a single point in time involving both qualitative and quantitative research approaches. This design was preferred because it enables the researcher to collect a lot of data in a short and limited time (Mugenda and Mugenda, 1999). The qualitative approach gave precise and testable expression to quantitative ideas. The population for the study comprised all SACCO members. A sampling frame of SACCOs in Soroti District was obtained from the District Commercial Officer. Eleven out of thirty SACCOs were purposively selected based on the active SACCOs that submitted monthly loan status reports to the District Commercial Officer and those that were operational. A sample size of two hundred fifty seven (257) out of 780 respondents was obtained using Krejcie and Morghan (1970)'s table for determining large sample sizes. The households were then selected using simple random sampling.

Research assistants conducted face to face interviews in the local language (Ateso) with the household head. Questions in the instrument focused on household's social networks and how these social networks influenced credit use decisions through the various social support provided at the time of utilizing credit. The design of the questions utilized the name generator approach because it generates manageable lists of network members (Campbell and Lee, 1991). Through the name generator approach, household network information was collected on persons from whom household received instrumental, emotional and social companionship support (Vander Poel, 1993). For every individual named as a source of support, information on various social support dimensions was procured including network composition. In addition, the socio demographic characteristics of the household head were compiled, including age, educational level and marital status from which information on network heterogeneity was generated.

Network composition and heterogeneity were examined using descriptive statistics and associations with socio demographic variables were analyzed. Descriptive statistics were used for variables from questions relating to network composition, heterogeneity and social support for which respondents could indicate multiple responses. Cross tabulation between social networks and social support with the various SACCOs was done to obtain the percentage of social networks and social support dimensions within each SACCO. The percentages were then squared and sum of all squared percentages in the distribution obtained and used to calculate the index of qualitative variability (IQV) using a formula by Leon-Guerrero and Frankfort-Nachmias (2011):

$I Q V=k\left(100-\sum \mathrm{pct}^{2}\right) / 100^{2}(\mathrm{k}-1)$,

Where $\mathrm{k}=$ the number of categories, $\mathrm{N}=$ the total number of cases in the distribution; $\Sigma \mathrm{pct}^{2}=$ the sum of all squared percentages in the distribution.

This was done to assess the variation in social networks and social support within the different SACCOs. Network heterogeneity was obtained by cross tabulating the IQVs of the different SACCOs with the socio demo graphic characteristics of the respondents and Chi-quare analysis was used to determine the significant demographic variables influencing the variability of social networks and social support within the different SACCOs. The binary logistic 
Table 1. Composition of household social network for accessing essential social support.

\begin{tabular}{lccc}
\hline Network composition & Instrumental support (\%) & Emotional support (\%) & Social companionship (\%) \\
\hline SACCO staff & 13.4 & 0 & 0 \\
SACCO members & 6.2 & 0 & 0 \\
NGOs & 12 & 0 & 0 \\
Opinion leaders & 48.8 & 100 & 0 \\
Friends & 73.7 & 50 & 100 \\
Family members & 45.9 & 50 & 50 \\
Media & 3.3 & 0 & 0 \\
\hline
\end{tabular}

Source: author

regression model was then used to determine the influence of social networks and social support on credit utilization using IQV values as independent variables. The Index of Qualitative variability is a measure of variability for nominal variables. It is based on the ratio of the total number of differences in the distribution to the maximum number of possible differences within the same distribution. The index can vary from 0.00 to 1.00 . When all the cases in the distribution are in one category, there is no variation (diversity) and IQV is 0.00 . In contrast, when the cases in the distribution are distributed evenly across the categories, there is maximum variation. The index of qualitative variability was used because it enables further analysis like regression analysis to be carried which is important in this study so as to determine the influence of social networks (sources of support) on credit utilization which is not possible using percentages (Leon-Guerrero and Frankfort-Nachmias (2011).

The IQV of the eleven SACCOs were calculated and used as independent variables in the logistic regression analysis. Logistic regression was used because it allows continuous as well as categorical independent variables with a dichotomous dependent variable (Dershem and Gzirishuili, 1998). In this study, credit utilization is the dependent variable measured as $1=$ when household used credit for production and $0=$ when households used credit for consumption.

\section{RESULTS}

\section{Network composition}

From the analysis of multiple responses, the study established the main sources of support for instrumental, emotional and social companionship (Table 1). Friends constituted the main sources of instrumental support $(73.7 \%)$, mainly providing funds for repayment, followed by opinion leaders $(48.8 \%)$ who mainly lobbied funds from SACCOs and family members (45.9\%), mainly providing collateral and funds for repayment. Emotional support mainly came from opinion leaders $(100 \%)$, followed by friends and family members (50\%). Social companionship was mainly provided by friends (100\%), followed by family members $(50 \%)$. Relatively limited support was provided by the media, NGOs, SACCO staff and SACCO members.

\section{Network heterogeneity}

Table 2 shows the wide variation in social networks in the
SACCOs and the significant socio demographic factors influencing the variation. Kamuda SACCO with an IQV of 0.91 , is the most diverse SACCO, followed by Katine and Soroti SS with an IQV of 0.89 . The age of the respondent was a significant factor $(P<0.05)$ influencing the variability of social networks. Respondents of age group 31 to 41 accounted for $66.7 \%$ of social network variability within Mid Kyoga SACCO. The sex of the respondent was also significant at $P<0.05$, influencing the diversity of social networks with male respondents from Mid Kyoga SACCO contributing $100 \%$ of the social network variability, followed by $86.7 \%$ of male respondents from Kamuda SACCO. Level of education was significant at $\mathrm{P}<0.00$ with tertiary level influencing $87.5 \%$ of the variability of social network. Occupation of the borrowers was also significant $(P<0.00)$ with farming influencing $83.3 \%$ of the variability of social network.

\section{Influence of social networks on credit utilization}

The results of the binary regression analysis of the influence of social networks on credit utilization are presented in Table 3 . The IQV of 0.77 had a negative coefficient of 1.390 and was significant at $P<0.05$ level of significance and the IQV of 0.89 had a negative coefficient of 1.878 and was significant at 0.05 level of significance.

\section{Influence of social support on credit utilization}

The binary logit regression was used to analyze the influence of social support on credit utilization. The IQV values of the SACCOs were used as the independent variables in the model. The results of the binary regression analysis of the influence of social support on credit utilization are presented in Table 4. All the IQVs had positive coefficients and were significant except the IQV of 0.68. The IQVs of $0.23,0.40,0.44$ and 0.78 had positive coefficients of $3.268,2.216,1.878$ and 2.565, respectively, and were significant at $P<0.01$ level of significance. The IQVs of $0.34,0.59$ and 0.74 had positive coefficients of 2.303, 1.529 and 1.674 and were 
Table 2. Network heterogeneity.

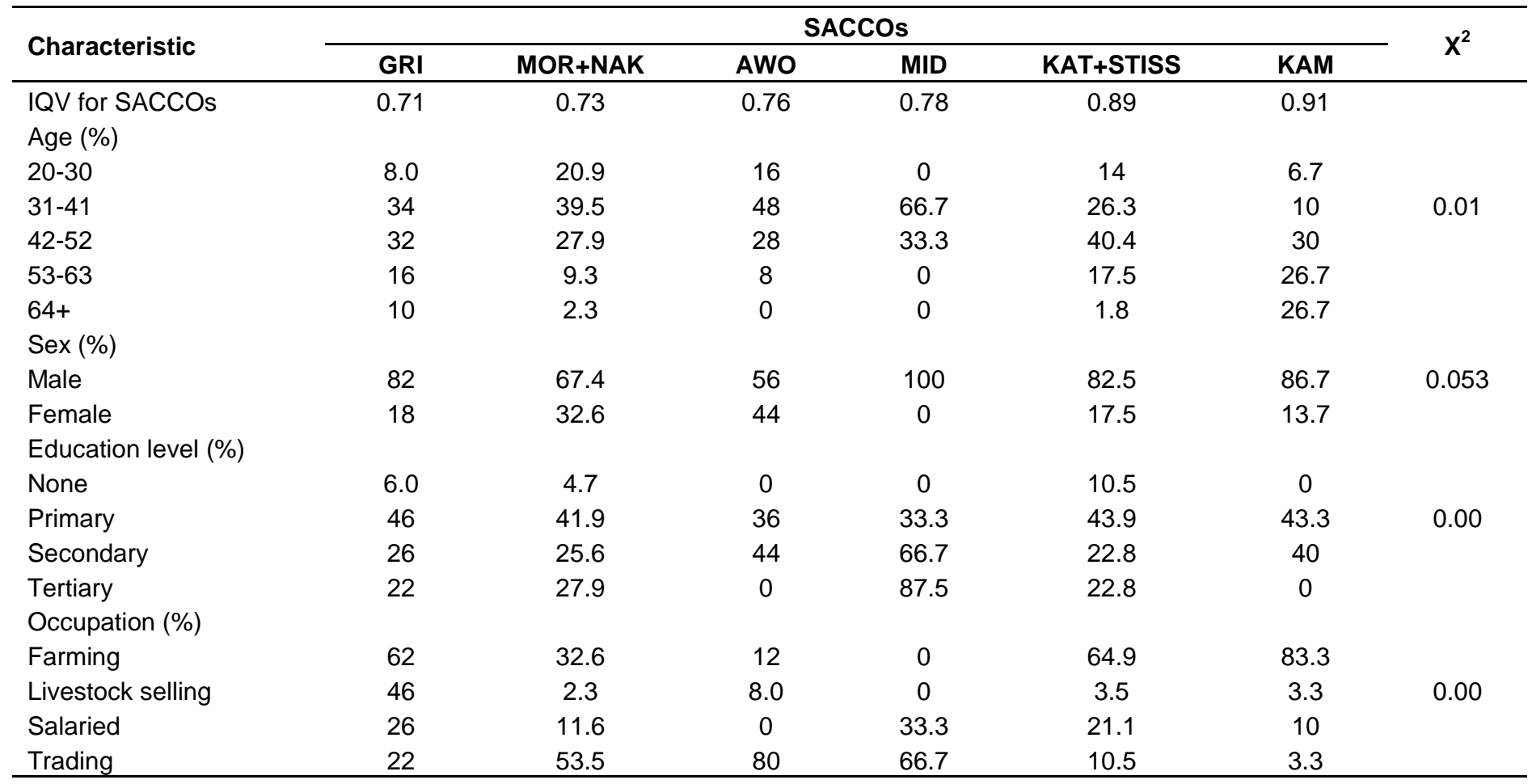

$\mathrm{GRI}=$ Gweri, MOR = Moruapesur, NAK = Nakatunya, AWO = Awoja, MID = Mid Kyoga, KAT = Katine, STISS = Soroti SS, KAM $=$ Kamuda, $\mathrm{X}^{2}=\mathrm{Chi}-$ Square.

Table 3. Logistic regression results for the influence of social networks on credit utilization as measured by IQVs for the SACCOs.

\begin{tabular}{llccc}
\hline SACCO & IQV & $\boldsymbol{\beta}$ & $\operatorname{Exp}(\boldsymbol{\beta})$ & P value \\
\hline GWRI+ EJOK & 0.71 & 0.221 & 1.248 & 0.638 \\
MOR+NAK & 0.73 & 0.681 & 1.975 & 0.174 \\
AWO & 0.76 & -0.348 & 0.708 & 0.522 \\
STIM+ STCH & 0.77 & -1.390 & 0.658 & $0.035^{\text {×x }}$ \\
MID & 0.78 & 20.935 & 1.235 & 0.999 \\
KAT+STISS & 0.89 & -1.878 & 0.153 & $0.004^{\text {xxx }}$ \\
KAM & 0.91 & -0.444 & 0.641 & 0.328 \\
\hline
\end{tabular}

2log likelihood $=315.186$, Cox \& Snell $R$ square $=0.134$, Nagelkerke $R$ square $=0.179, x x x=$ significance at $1 \%, x x=$ Significance at $5 \%, I Q V=$ Index of qualitative variability, GRI= Gweri, MOR= Moruapesur, $\mathrm{NAK}=$ Nakatunya market vendors, $\mathrm{AWO}=\mathrm{Awoja}, \mathrm{MID}=$ Mid Kyoga, KAT= Katine, STISS= Soroti SS, KAM= Kamuda, STM= Soroti Market Vendors, STCH= Soroti teachers, EJOK= Ejoke Edeke, SACCO = Savings and Credit Cooperative.

significant at $P<0.05$ level of significance. The IQV of 0.31 had a positive coefficient and was significant at $10 \%$ level of significance.

\section{DISCUSSION}

The main purpose of this paper was to examine the influence of social networks and social support on credit utilization within SACCOs. This study revealed that friends and family members provided major sources of support towards credit utilization providing both instrumental, emotional and social companionship, especially in the form of advice, funds for repayment, labour and collateral for accessing credit. Friends were more influential in providing support towards credit utilization by providing social companionship in terms of encouraging members to join or form groups or SACCOs 
Table 4. Logistic regression results for the influence of social support on credit utilization.

\begin{tabular}{lcccc}
\hline SACCO & IQV & $\boldsymbol{\beta}$ & $\operatorname{Exp}(\boldsymbol{\beta})$ & P value \\
\hline STIM & 0.23 & 3.268 & 26.250 & $0.000^{\mathrm{xxx}}$ \\
KAT & 0.31 & 1.139 & 3.125 & $0.094^{\mathrm{x}}$ \\
EJOK & 0.34 & 2.303 & 10.000 & $0.01^{\mathrm{xx}}$ \\
GWRI + MOR & 0.40 & 2.216 & 9.167 & $0.00^{\mathrm{xxx}}$ \\
KAM & 0.44 & 1.878 & 6.538 & $0.004^{\mathrm{xxx}}$ \\
AWO & 0.59 & 1.529 & 4.615 & $0.024^{\mathrm{xx}}$ \\
STISS+MID & 0.68 & 22.812 & 8.077 & 0.999 \\
NAK & 0.74 & 1.674 & 5.333 & $0.011^{\mathrm{xx}}$ \\
STCHRS & 0.78 & 2.565 & 13.000 & $0.001^{\mathrm{xxx}}$ \\
\hline
\end{tabular}

2log likelihood $=314.917$, Cox \& Snell $R$ square $=0.134$, Nagelkerke $R$ square $=0.180, x=$ significant at $10 \%, x x=$ Significant at $5 \%, x x x=$ significant at $1 \%, I Q V=$ Index of qualitative variability, GRI $=$ Gweri, MOR= Moruapesur, NAK = Nakatunya market Vendors, AWO= Awoja, MID= Mid Kyoga, KAT= Katine, STISS= Soroti SS, KAM= Kamuda, STM= Soroti Market Vendors, STCH= Soroti teachers, EJOK= Ejoke Edeke, SACCO = Savings and Credit Cooperative.

in order to benefit from government programs, to save, to improve livelihoods and increase business capital and provide repayment. By having most of their supportive networks with friends, members have greater connections and access to information, advice and funds necessary to facilitate access and repayment of credit hence utilize credit efficiently. This finding agrees with the finding of Richey et al. (1996) who found that most parents perceived their support needs generally being fulfilled by their family and friends.

The variability of the social networks within SACCOs was significantly influenced by age, sex, level of education and occupation of the respondents. Education was a significant factor influencing the variability of social networks within SACCOs. Respondents with tertiary level of education significantly influenced the variability of social networks in the SACCOs. This implies that respondents with higher levels of education have greater connections with people of different levels and cultures and are more exposed to acquire more resources such as funds to facilitate repayment credit. This point is consistent with the finding of Bastani (2007) which discovered that education allows people to have relations with people from different contexts and respondents with higher levels of education have larger networks. Obaa and Mazur (2016) also found that there were no meaningful linkages with regard to household heads with no or low level of education.

Age of the respondents was also a significant factor influencing variability of social networks in the SACCOS with respondents of age groups between 31 to 40 significantly influencing the variability of social networks within the SACCOs. This is the active age when people get married and the number of siblings and consequently the number of immediate kin increases in their network creating greater opportunities of support towards credit utilization in terms of labour, land for collateral and funds for repayment of credit. This finding is in agreement with Bastani (2007) who in his study on men's and women' social networks in Tehran, also noted that older respondents have more children and siblings in their networks.

Male respondents significantly influenced the variability of the social networks. This implies that majority of the SACCO members are married and have more children and siblings in their networks that provide a potential source of support for gaining access to resources such as labour, and information during investment of credit. This finding is in line with Wale et al. (2013) argument that male respondents have high involvement in outdoor activities and better access to information than their female counterparts. The general pattern of these variables indicates that persons who more economically, educationally and occupationally privileged form larger networks and establish more close ties to nonkin of various types than less privileged persons (Moore, 1990). This study also revealed that the variability of the social networks was generally high but negatively related to credit utilization. This means that an increase in the number of social networks of a borrower will cause a decrease in the use of credit for intended productive purposes. This leads us to reject the hypothesis that the more varied the social networks, the more credit will be utilized for consumption. This implies that the variability of social networks does not necessarily translate into effective utilisation of credit. This is because not all network members may be educationally or economically able to offer financial support towards credit utilization given the prevalence of poverty in the rural areas. This finding is in agreement with Tracy and Whittaker (1987)'s argument that not all social exchanges are supportive and that the size of the social network does not 
necessarily reflect the amount of support perceived or available. On the contrary, a high variability of social networks especially kin networks offer greater access to resources such as land, labour and other resources (Obaa and Mazur, 2016) necessary for effective utilization of credit. Therefore, interventions to increase productive use of credit should be geared towards borrowers with fewer network members especially during formation of groups and associations.

This study further revealed that effective utilization of credit is not necessarily dependent on the variability of social support accessed from social networks. This leads us to reject the hypothesis that the higher the variability of social support, the more credit will be utilized effectively. The possible explanation could be that the support needed by an individual will depend on the problem at hand and on the characteristics of the individual in the social network. This finding is not consistent with Obaa and Mazur (2016)'s argument that the resources accessed from social networks are dependent on the network diversity. Hence interventions to strengthen social support need to target persons who are more economically, educationally and occupationally privileged.

\section{CONCLUSION AND RECOMMENDATION}

This study examined the influence of social networks and social support on credit utilization within SACCOs. From this study, the variability of the social networks does not determine productive utilisation of credit due to differences in the age and household size that call for different needs and responsibilities.

Also, productive utilization of credit is not necessarily dependent on the variability of social support accessed from social networks but on the problem faced during crisis moment and the characteristics of the network members such as level of education and occupation.

As far as the implication of these findings for effective utilisation of credit is concerned, interventions to increase productive use of credit should be geared towards borrowers with fewer network members, especially during formation of groups and associations. Secondly, interventions to strengthen social support should target network members who are more economically, educationally and occupationally privileged.

\section{CONFLICT OF INTERESTS}

The authors have not declared any conflict of interests.

\section{ACKNOWLEDGEMENTS}

The authors gratefully acknowledge RUFORUM and the Carnegie Cooperation of New York for the financial support provided for funding tuition, research, authorship and publication of this article

\section{REFERENCES}

Bastani S (2007). Family comes first: Men's and women's personal networks in Tehran. Soc. Networks 29(3):357-374.

Campbell E, Lee BA (1991). Name generators in surveys of personal networks. Soc. networks 13(3):203-221.

Chai S, Chen Y, Huang B, Ye D (2016). Social networks and informal financial inclusion. Xi'an Jiaotong-Liverpool University, Research Institute for Economic Integration 4.

Clark B, Hasan I, Lai H, Li F, Siddique A (2014). Delinquencies and Social Capital: Do Strong Social Networks Deter Consumer Default? In Current Issues in Housing Finance. Florida State University.

Cohen S, Underwood LG, Gottlieb BH (2000). Social support measurement and intervention: A guide for health and social scientists. Oxford University Press.

Dasqupta S, Dey G (2015). A Study on Utilisation of Credit by Marginal Farmers in Nadia District of West Bengal. Econ. Affairs 60(2):181186.

Dershem L, Gzirishuili D (1998). Informal social support networks and household vulnerability: Empirical findings from Georgia. World Dev. 26(10):1827-1838.

Gottlieb BH, Bergen AE (2010). Social support concepts and measures. J. Psychosom. Res. 69(5):511-520.

Idris AJ, Agbim KC (2015). Micro-credit as a strategy for poverty alleviation among women entrepreneurs in Nasarawa State, Nigeria. J. Bus. Stud. Q. 6(3):122-143.

Kebede W, Butterfield AK (2009). Social networks among poor women in Ethiopia. Int. Soc. Work. 52(3):357-373.

Knoke D, Yang S (2008). Social network analysis. Sage 154.

Krejcie RV, Morgan DW (1970). Determining sample size for research activities. Educ. Psychol. Measure. 30(3):607-610.

Leon-Guerrero A, Frankfort-Nachmias C (2011). Essentials of social statistics for a diverse society. Sage Publications 1-337.

Moore G (1990). Structural determinants of men's and women's personal networks. Am. Soc. Rev. 726-735.

Mugabi N (2010). Micro-credit utilization and its impact on household income: A comparative study of rural and urban areas in Iganga district. Master Thesis, Makerere University).

Mugenda OM, Mugenda AG (1999). Research method: Quantitative and qualitative approaches. Acts Press, Nairobi, Kenya.

Muhumuza W (2013). Revisiting state intervention: State-sponsored micro-credit and poverty reduction in Uganda. Afr. J. Pol. Sci. Int. Relations 7(3):121-132.

Mwangi J, Kimani E (2015). Factors Influencing Participation of men and women in Informal Finance Groups in Gachagi Informal Settlement in Thika Sub-County, Kenya. Int. J. Human. Soc. Stud. $3(1): 42-48$

Nathan OF, Banga M, Mukungu A (2004). Microfinance and Poverty Reduction in Uganda: Achievements and Challenges. Economic policy research centre (EPRC).

Obaa BB, Mazur RE (2016). Social network characteristics and resource access among formerly displaced households in Lira, Uganda. Disasters 41(3):468-486.

Okten C, Osili UO (2004). Social networks and credit access in Indonesia. World Dev. 32(7):1225-1246.

Oluyombo D (2013). Impact of Cooperative Societies Savings Scheme in Rural Finance: Evidence from Nigeria. J. Co-operative stud. 46(1):5-15.

Richey CA, Hodges VG, Agbayani-Siewert P, Petitt K (1996). Social support characteristics among nonclinical African-American and Filipino-American parents with school-age children. Children Youth Services Rev. 18(8):659-692.

Tracy EM, Whittaker JK (1987). The evidence base for social support interventions in child and family practice: Emerging issues for research and practice. Children Youth Services Rev. 9(4):249-270.

Vander Poel MG (1993). Delineating personal support networks. Social Networks 15(1):49-70. 
Vedamurthy KB, Dhaka JP, Sirohi S (2015). Analysis of institutional credit for dairy farming in Karnataka: A study of Shimoga Milk Zone. Indian J. Dairy sci. 68(3):282-286.
Wale G, Endalew E, Haji J (2013). Determinants of microfinance service utilization: The case of Dire Dawa, Ethiopia. G. S. J. Econ. 1(1):1-12. 